\title{
MULTIMEDIA INTERAKTIF: MEDIA BELAJAR UNTUK MEMBUAT PASPOR RI MELALUI SIMULASI
}

\author{
Evaliata Br Sembiring ${ }^{(1)}$ dan Nurrahmah ${ }^{(2)}$ \\ Program Studi Teknik Multimedia dan Jaringan, Politeknik Negeri Batam \\ Jl. Ahmad Yani Batam Center-Batam, 2946I, Indonesia \\ Email: (I)eva@polibatam.ac.id, (2)_nurrahmahI5@gmail.com
}

\begin{abstract}
Abstrak
APM is an Innovation in 2017 implemented at the Immigration class II Tanjung Balai Karimun Office in making an Indonesian passport. People complain about the new system. Generally, there is a lot of files that need to be prepared and confused to run the procedure. The development of technology can answer these complaints through various media. One of the media that can be used is Interactive Multimedia. Through this media, people can be guided in preparing files and carrying procedures under the activities carried out at the immigration office. Therefore, the model is applied in the form of simulation.

This research applies the ADDIE model so that the implementation started with a needs analysis, system design based on needs, media development, implementation and evaluation of the applied media. the results of the study are: (1)The results of the needs analysis regarding information on submitting an application for an Indonesian passport there are $69.87 \%$ of applicants not yet aware of the passport application procedures through the APM application; (2)Interactive multimedia about the Indonesian passport application simulation using the APM application produced as one of the information media for the community by applying the ADDIE model packaged in format (SWF) and (exe), applying the navigation button feature for user interactivity, content format in the form of text, images, and 2D animation video's; (3)Formative and summative evaluation results enable interactive multimedia as a learning medium to assist the community in completing files and applying for an Indonesian passport in accordance with actual implementation at the immigration office.
\end{abstract}

Keywords: APM, Multimedia Interaktif, Simulasi, ADDIE

\section{PENDAHULUAN}

APM (Anjungan Paspor Mandiri) merupakan inovasi baru tahun 2017 oleh kantor Imigrasi kelas II Tanjung Balai Karimun dalam pembuatan paspor RI (Republik Indonesia). APM dapat dimanfaatkan untuk melayani masyarakat (pemohon pembuatan paspor RI) dengan berbantukan PC (Personal Computer) dan pemindai yang berada di Kantor Imigrasi, kemudian pemohon melakukan pengisian data diri sendiri (Widodo \& Hadi, 2017). Ada banyak berkas yang perlu disiapkan oleh pemohon paspor, kemudian diminta menemui beberapa petugas layanan, yang menyebabkan pemohon kebingungan sehingga tidak jarang menyimpulkan pengurusan paspor sulit, ribet dan lain-lain. Berdasarkan hal itu, sangat perlu disosialisasikan tentang layanan APM ini kepada masyarakat seperti alur atau prosedur penggunaan sistem layanan, dokumen yang perlu dipersiapakan dan lainnya. Berdasarkan data yang diperoleh tahun 2017 dan 2018, diketahui bahwa belum banyak masyarakat yang mengetahui alur penggunaan pelayanan baru APM. Kendala yang dihadapi Kantor Imigrasi Kelas II 
Tanjung Balai Karimun seperti minimnya pengetahuan masyarakat terhadap informasi dokumen yang diperlukan serta alur APM. Hal ini berdampak pada terjadinya penumpukan pada pelayanan informasi yang sebagian besar melayani informasi penggunaan APM. Pelayanan yang diberikan kepada masyarakat menjadi kurang efesien dan efektif.

Salah satu solusi yang memungkinkan untuk penyelesaian masalah tersebut adalah penyajian informasi tentang layanan baru APM dengan memanfaatkan teknologi yang semakin dekat dengan masyarakat. Teknologi yang dimaksud adalah media yang dapat dimanfaatkan untuk menyebarkan informasi seluas-luasnya, yaitu media digital seperti video, animasi, media online (website, sosial media), multimedia interaktif dan lainnya. Aplikasi multimedia interaktif sudah dikembangkan dengan berbagai kepentingan seperti: media simulasi untuk meningkatkan aktivitas belajar siswa (Ahmad \& Bunga, 2015); media promosi dalam bentuk game (Oktafitriani, Hermana, Perdana, \& Yesmaya, 2016), media promosi produk dan jasa dalam bentuk video animasi 2D (Sinta \& Sembiring, 2017), media pembelajaran dengan model tutorial (Sembiring, Wahyuni, \& Anurogo, 2018) dan media pembelajaran dalam bentuk e-learning (Pratomo \& Irawan, 2015).

Multimedia interaktif terdiri dari beberapa jenis yaitu tutorial, latihan (drill), simulasi dan demontrasi (Oka, 2017). Multimedia jenis simulasi adalah menggunakan situasi asli yang akan benar-benar dihadapi dari sebuah sistem. Simulasi berfungsi untuk menirukan suatu kondisi yang nyata sesuai keaadaan yang akan dihadapi dalam suatu kondisi tertentu yang sulit dijangkau untuk memberikan sensasi pengalaman terhadap pengguna. Oleh sebab itu, dalam penelitian ini dibuat sebuah media yang interaktif untuk menggambarkan proses layanan APM dalam pembuatan paspor RI beserta dokumen-dokumen yang perlu dipersiapkan. Bentuk produk yang dibuat adalah multimedia interaktif menggunakan model simulasi.

Simulasi diperlukan untuk membantu pemohon menyiapkan keperluan dan informasi apa saja yang dibutuhkan saat permohonan pengajuan paspor RI. Selain itu, simulasi berfungsi untuk menirukan keadaan nyata dari proses permohonan pengajuan paspor sehingga pemohon tidak lagi kebingungan ketika akan membuat paspor RI. Diharapkan melalui simulasi ini dapat digunakan untuk mengatasi keterbatasan dalam jarak dan ruang seperti dalam kondisi pembuatan paspor. Pemohon yang akan mengajukan permohonan paspor tidak perlu menghabiskan waktu terlalu lama di Kantor Imigrasi untuk membuat paspor jika pemohon dapat mengetahui alur permohonan paspor dan menyiapkan dokumen apa saja yang diperlukan ketika akan membuat paspor.

Pembuatan produk multimedia interaktif ini menerapkan metode $R$ and $D$ (Research and Development) dengan model ADDIE (Analyze, Design, Develo, Implement and Evaluate). Model ini memiliki tahapan kerja yang sederhana dan efektif digunakan dalam pengembangan produk pembelajaran (Branch, 2009), dan paling popular ("The ADDIE Model Infographic," 2017). Sementara simulasi tentang pembuatan paspor RI melalui layanan APM merupakan salah satu model pembelajaran bagi masyarakat agar dapat membantu pemohon untuk memahami dan melakukan prosedur atau alur pembuatan paspor RI dengan benar.

\section{METODE}

Penelitian ini menggunakan metode Research and Development ( $R$ and $D$ ) dengan menerapkan model ADDIE (Analyze, Design, Develop, Implement and Evaluate) seperti ditunjukkan pada gambar 1. 


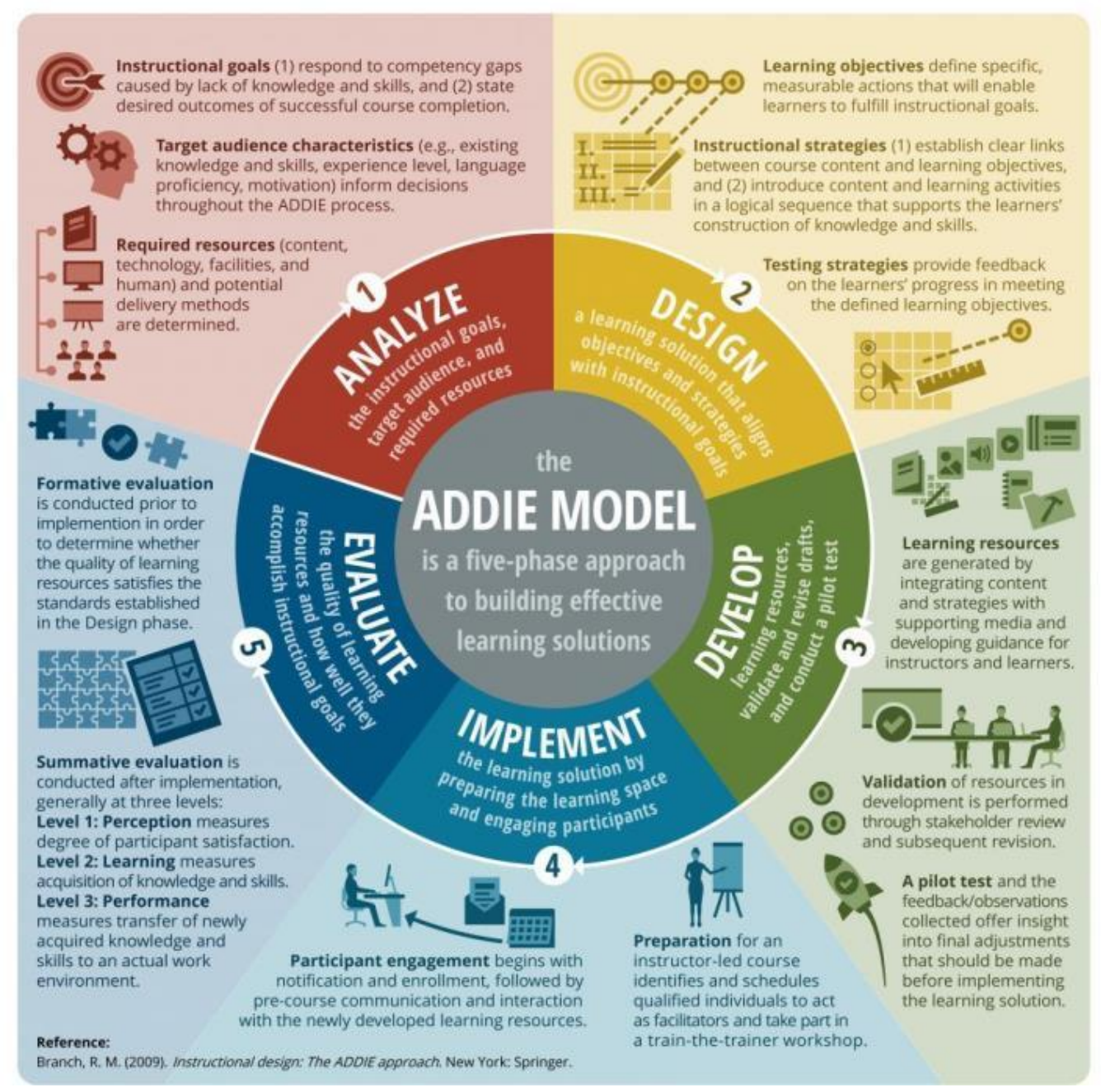

\section{Gambar1. Tahapan Kerja Model ADDIE}

(Sumber:(“The ADDIE Model Infographic,” 2017))

\section{Analyze (Menganalisa)}

Kegiatan yang dilakukan pada tahap ini adalah menentukan penyebab dari permasalahan yang berkaitan dengan kebutuhan untuk pengalaman belajar. Oleh karena itu tujuan proses ini adalah untuk menemukan permasalahan yang dapat diselesaikan melalui pengembangan produk. Tiga proses yang dilakukan yaitu:

a. Menentukan Tujuan Pembelajaran dengan merespon kesenjangan kompetensi karena kurangnya pengetahuan dan ketrampilan dalam masalah tertentu dan menentukan hasil yang diinginkan dari penyelesaian masalah tersebut.

b. Mengidentifikasi karakteristik target responden, seperti: pengetahuan dan keterampilan saat ini, tingkat pengalaman, kemahiran bahasa, motivasi yang ada.

c. Menentukan kebutuhan sumber daya, seperti konten produk, teknologi yang digunakan, fitur yang dibutuhkan, dan metode distribusi produk yang akan dihasilkan.

Analisis kebutuhan pembuatan produk dalam bentuk multimedia interaktif diawali dengan penyebaran angket kepada masyarakat sekitar, yang dikategorikan berdasarkan usia. Informasi yang digali adalah pengetahuan 
tentang APM dan Sumber atau media pengetahuan yang digunakan. Hasil penggalian informasi disajikan pada Tabel 1.

Tabel 1 Pengetahuan Responden Tentang APM (Data Tahun 2018)

\begin{tabular}{|c|c|c|c|c|c|c|}
\hline \multirow{2}{*}{$\begin{array}{l}\text { Umur } \\
\text { (tahun) }\end{array}$} & \multicolumn{2}{|c|}{$\begin{array}{c}\text { Pengetahuan } \\
\text { tentang APM }(\%)\end{array}$} & \multicolumn{4}{|c|}{$\begin{array}{c}\text { Sumber Pengetahuan } \\
\text { tentang APM/Pengurusan Paspor }\end{array}$} \\
\hline & 1 & 2 & 1 & 2 & 3 & 4 \\
\hline $0-16$ & - & 100,00 & - & 100,00 & - & - \\
\hline $17-30$ & 44,12 & 55,88 & 58,82 & 14,70 & 11,76 & 14,70 \\
\hline $31-40$ & 40,00 & 60 & 22,67 & 6,67 & - & 26,67 \\
\hline $41-50$ & 13,33 & 86,67 & 46,67 & 26,67 & 20,00 & 6,67 \\
\hline $51-60$ & 25,60 & 75,00 & 25,00 & 62,50 & - & 12,5 \\
\hline $61-70$ & - & 100,00 & 50,00 & 50,00 & - & - \\
\hline Jumlah & 30,12 & 69,87 & 48,19 & 30,12 & 8,43 & 13,25 \\
\hline Keterangan & \multicolumn{2}{|c|}{$\begin{array}{l}1=\text { Tahu } \\
2=\text { Tidak Tahu }\end{array}$} & \multicolumn{4}{|c|}{$\begin{array}{l}3=\text { Petugas Imigrasi } \\
4=\text { Keluarga } \\
5=\text { Teman } \text { Kerabat } \\
6=\text { Intemet }\end{array}$} \\
\hline
\end{tabular}

Berdasarkan data yang diperoleh seperti disajikan pada Tabel 1, terdapat $69.87 \%$ pemohon pembuatan paspor RI belum mengetahui informasi layanan APM. Oleh sebab itu, ditentukan beberapa hal terkait dengan solusi dari minimnya informasi tentang layanan APM seperti disajikan pada Tabel 2.

Tabel 2 Analisis Kebutuhan Media Pembelajaran

\begin{tabular}{|c|c|}
\hline Item Analisis & Keterangan \\
\hline $\begin{array}{c}\text { Tujuan } \\
\text { Pembelajaran }\end{array}$ & $\begin{array}{l}\text { Menyajikan informasi tentang alur layanan APM dan dokumen-dokumen yang perlu } \\
\text { dipersiapkan }\end{array}$ \\
\hline $\begin{array}{l}\text { Karakteristik } \\
\text { Responden }\end{array}$ & $\begin{array}{l}\text { - Target pengguna: masyarakat khususnya daerah Tanjung Balai Karimun } \\
\text { - Rentang usia 17-60 tahun } \\
\text { - Pengetahuan tentang layanan APM } \\
\text { - Motivasi pengurusan paspor } \\
\text { - Sumber informasi tentang pengurusan parpor: petugas imigrasi, keluarga, kerabat dan media } \\
\text { online }\end{array}$ \\
\hline $\begin{array}{l}\text { Kebutuhan } \\
\text { Sumber daya }\end{array}$ & $\begin{array}{l}\text { - Konten produk: prosedur/alur layanan APM } \\
\text { - Teknologi yang digunakan adalah multimedia interaktif dengan menggunakan animasi 2D } \\
\text { - Format produk: .exe (infografic) dengan konten: teks, animasi 2D, video } \\
\text { - Media distribusi produk: online }\end{array}$ \\
\hline
\end{tabular}

\section{Design (Merancang)}

Tahapan ini bertujuan untuk mendeskripsikan struktur materi, strategi dan pengalaman pembelajaran yang diinginkan. Dokumen yang dihasilkan pada tahap ini blueprint atau rancangan untuk pengembangan materi. Tiga proses yang dilakukan adalah:

a. Menentukan tujuan pembelajaran yaitu tindakan yang spesifik dan terukur sehingga memungkinkan pengguna memahami tujuan pembelajaran. Pada tahap ini ditentukan konsep produk yang akan 
dimanfaatkan sebagai media pembelajaran bagi masyarakat untuk memehamai tata cara dan dokumen yang harus dipersiapkan dalam pembuatan paspor yaitu:

$\checkmark$ Menyajikan informasi dalam bentuk multimedia interaktif

$\checkmark$ Beberapa fitur yang disediakan bagi pengguna adalah untuk memilih menu pilihan informasi yang belum dipahami menggunakan model klik tombol dan disediakan icon dalam bentuk gambar sehingga dapat membantu pengguna memahami informasi dengan cepat.

$\checkmark$ Rancangan kuisioner untuk pengguna agar diketahui sejauh mana pengetahuan pengguna setelah menggunakan produk multimedia interaktif berdasarkan parameter clarity, usefulness, dan relevancy)

$\checkmark$ Melakukan pengujian melalui evaluasi formatif yaitu pengujian kepada ahli (one to one evaluation) yaitu pihak dari Imigrasi. Selanjutnya evaluasi sumatif berdasarkan parameter persepsi, pembelajaran dan kemampuan yaitu Masyarakat/pemohon paspor.

b. Menentukan strategi pembelajaran yang dapat membangun hubungan yang jelas antara konten dan tujuan pembelajaran serta memperkenalkan konten dan kegiatan pembelajaran dalam urutan logis untuk mendukung konstruksi pengetahuan dan keterampilan pengguna. Strategi pembelajaran yang diterapkan dalam multimedia interaktif adalah melihat panduan, menyajikan informasi tentang paspor dan menampilkan video dalam bentuk motion graphic tentang simulasi alur APM dalam bentuk Video. Berdasarkan hal ini ditetapkan struktur navigasi produk seperti ditunjukkan pada Gambar 2.

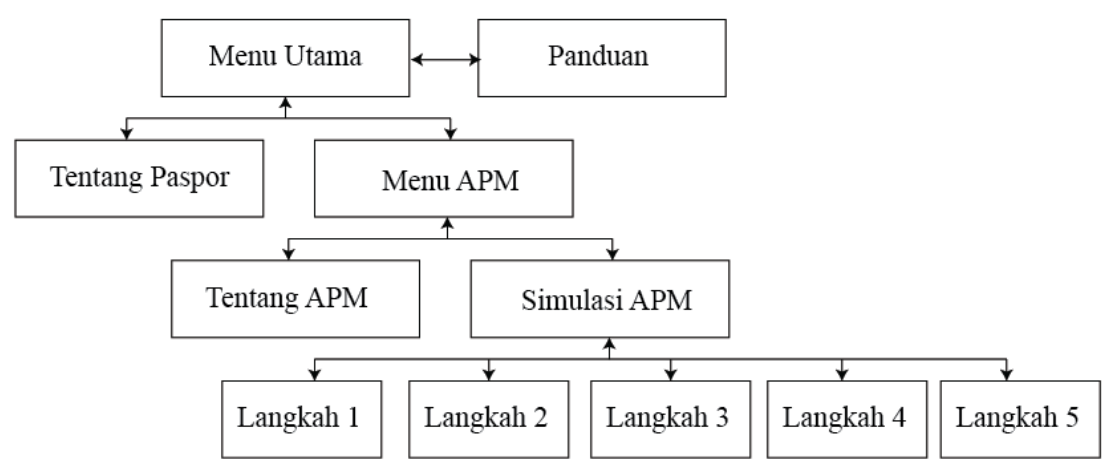

Gambar 2 Struktur Navigasi Multimedia Interaktif

c. Menentukan strategi pengujian dengan memberikan umpan balik tentang kemajuan pemahaman pengguna untuk mencapai tujuan pembelajaran yang ditetapkan yaitu melalui evaluasi formatif dan sumatif. Evaluasi berdasarkan data yang dikumpulkan melalui kuisioner kemudian dianalisis kemajuan pemahaman responden.

\section{Develop (Mengembangkan)}

Tahapan develop adalah menyusun materi sebagai solusi terhadap permasalahan dan menyediakan perangkat pendukung untuk implementasi, dengan beberapa hal yang perlu diperhatikan antara lain:

a. Sumber belajar dihasilkan dengan mengintegrasikan konten dan strategi dengan media pendukung dan mengembangkan panduan untuk instruktur dan peserta didik. Dalam hal ini sebagai instruktur adalah petugas Imigrasi dan peserta didik merupakan responden yang berasal dari masyarakat yang mengajukan 
permohonan Parpor RI. Konten materi multimedia pembelajaran yang dipersiapkan bersumber dari beberapa sumber literatur dari imigrasi, buku petunjuk imigrasi, internet dan layanan imigrasi.

b. Validasi sumber daya dalam pembangunan dilakukan melalui tinjauan pemangku kepentingan yaitu pihak Imigrasi dan revisi selanjutnya sesuai kebutuhan.

c. Uji coba dan umpan balik (observasi) yang dikumpulkan menawarkan wawasan tentang penyesuaian akhir yang harus dilakukan sebelum menerapkan solusi pembelajaran.

Pembuatan multimedia interaktif dibuat sebagai solusi dari tahapan analisis masalah yang dilakukan. Tahapan yang dilakukan meliputi tracing, coloring, dubbing, animating, dan coding sebagai berikut:

a. Tracing dan coloring karakter yang akan ditampilkan pada video animasi. Terdapat tiga karakter yaitu karakter pemohon, karakter petugas laki-laki, dan karakter petugas perempuan. Pembuatan karakter dilakukan di Adobe Photoshop CS6.

b. Dubbing suara narasi menggunakan perangkat ponsel. Format file suara dubbing .m4a dan .mp3.

c. Animating adalah membuat pergerakan objek-objek yang sebelumnya di tracing dan coloring di Adobe Illustrator. Objek tersebut kemudian di import ke dalam Adobe After Effect untuk proses animating. Pergerakan objek disesuaikan dengan dubbing narasi. Selain itu, ditambahkan teks, transisi dan efek. Kemudian di export dalam bentuk format .mp4.

d. File animating diolah kembali di software Adobe Premiere Pro. Ditambahkan di backsound, soundeffect, serta penampahan subtitle. Kemudian di export dalam bentuk .mp4.

e. Setelah enam video animasi selesai di buat, maka proses selanjutnya adalah membuat tampilan visual dan membuat tombol navigasi multimedia interaktif. Tampilan visual dibuat di Adobe Illustrator dan di export ke Adobe Flash untuk proses coding. Tampilan visual disesuaikan dengan perancangan storyboard.

f. Proses selanjutnya adalah menambahkan coding untuk mengaktifkan tombol navigasi di multimedia interaktif. Bahasa pemograman yang digunakan adalah Action Script 0.3 pada Flash. Kemudian import file efek suara untuk tombol. File eksternal video diberi link agar terhubung dengan multimedia interaktif. Project dipublisht dalam format .swf.

\section{Implement (Implementasi)}

Tahap implementasi yang dimaksudkan adalah tahap pengujian produk oleh pengembang. Tahapan ini dimaksudkan untuk melihat kesesuaian dalam pembuatan produk dan melakukan revisi kesalahan tersebut sampai sesuai dengan rancangan.

a. Persiapan untuk pembelajaran yang dipimpin instruktur mengidentifikasi dan menjadwalkan individu yang berkualifikasi untuk bertindak sebagai fasilitator dan mengambil bagian dalam pelatihan. Dalam hal ini dilakukan distribusi produk (multimedia interaktif) kepada responden, kemudian digunakan responden, selanjutnya diuji peningkatan pemahaman dari responden mengenai prosedur dan kelengkapan berkas pengajuan Paspor RI.

b. Keterlibatan peserta dimulai dengan pemberitahuan dan pendaftaran, diikuti dengan komunikasi prakursus dan interaksi dengan sumber belajar yang baru dikembangkan. Hal ini dilakukan dengan 
mencari responden secara online melalui media sosial dan juga secara offline yaitu menemui pemohom paspor di kantor Imigrasi.

\section{Evaluate (Evaluasi)}

Tahapan ini adalah menentukan pengalaman belajar. Proses yang dilakukan adalah analisis kepuasan, hasil belajar, dan sebagainya dari responden. Dua tahap proses evaluasi adalah formatif dan sumatif. Evaluasi formatif dilakukan dengan tiga tahap yaitu:

a. One-to-one evaluation adalah mengukur keefektifan produk berdasarkan aspek kejelasan (clarity), kegunaan (usefulness) dan relevansi (relevancy) bagi target pengguna.

b. Small group evaluation adalah membentuk kelompok kecil sebagai perwakilan dari dari kelompok khusus.

c. Field trial adalah uji coba lapangan dengan menguji komponen produk.

Evaluasi sumatif adalah proses mengumpulkan data dengan mengikuti hasil implementasi. Tujuan utama dari evaluasi sumatif adalah untuk membuktikan apakah pembelajaran memberikan dampak atau tidak. Ada tiga level evaluasi sumatif :

a. Perception (persepsi) adalah mengukur tingkat kepuasan pengguna.

b. Learning (pembelajaran) adalah mengukur akuisisi/pengambilan pengetahuan dan keterampilan.

c. Peformance (kemampuan) adalah mengukur pengetahuan dan keterampilan yang baru diperoleh untuk lingkungan sebenarnya.

\section{HASIL DAN PEMBAHASAN}

Penelitian ini menghasilkan sebuah produk sebagai media pembelajaran dalam bentuk Multimedia Interaktif. Pengguna sebagai peserta pembelajar dapat menggunakan media ini dengan fitur penuntun melalui gambar icon dan klik tombol seperti ditunjukkan pada gambar 3.
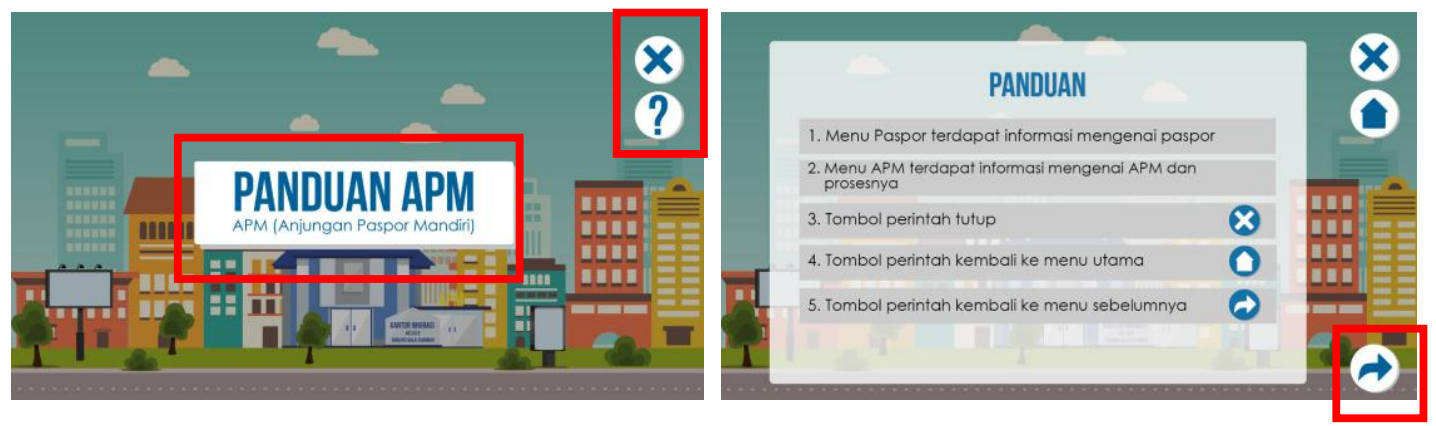

Gambar 3 Screen Shot Tampilan Penggunaan Tombol untuk Navigasi

Konten yang disediakan sesuai dengan yang ada di kantor Imigrasi dalam berbagai bentuk yaitu teks, gambar dan video. Penjelasan berkas dan prosedur pengajuan Paspor RI disimulasikan seperti pelaksanaan nyata di lingkungan Imigrasi dalam bentuk video. Terdapat enam video yang dihasilkan dan disajikan dalam bentuk animasi 2D seperti ditunjukkan pada gambar 4. Setiap video berisi tentang informasi lokasi kantor imigrasi, kelengkapan berkas-berkas permohonan, cara penggunaan aplikasi APM, proses foto dan wawancara dan 
pengambilan atau penerimaan paspor. Informasi yang disampaikan sesuai dengan sebenarnya yang terjadi di kantor imigrasi dalam melayani permohonan paspor RI.
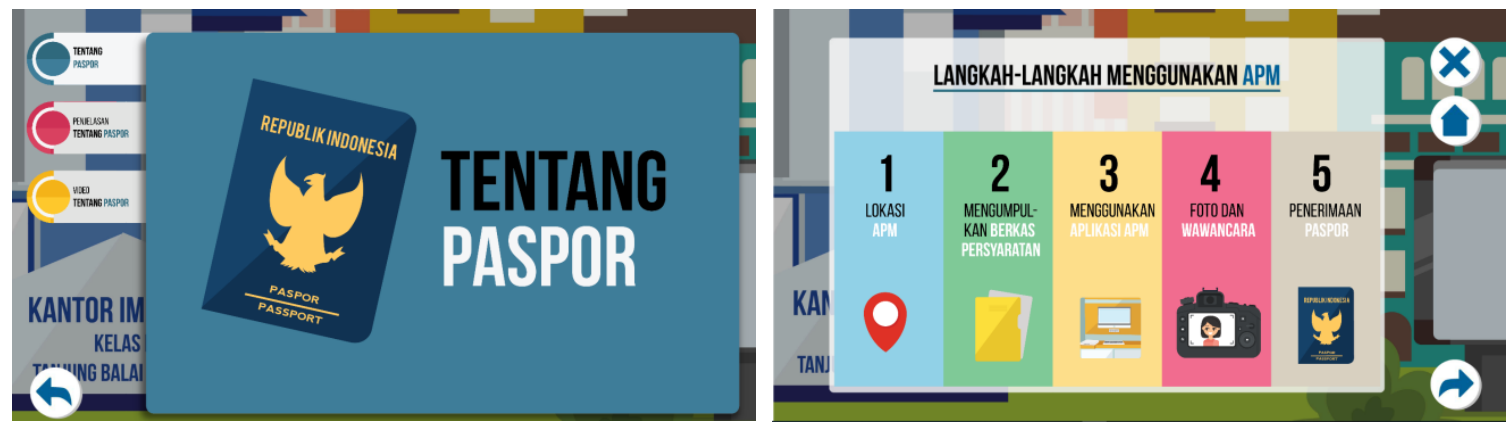

\section{Gambar 4 Screen Shot Tampilan Konten Multimedia Interaktif}

Berdasarkan hasil evaluasi yang dilakukan melalui 2 tahap yaitu evaluasi formatif dan sumatif, diperoleh hasil sebagai berikut:

\section{Evaluasi Formatif}

Evaluasi formatif menggunakan responden dari pihak imigrasi melalui tiga tahap, yaitu One-to-One, small group, dan field trial. Evaluasi ini dilakukan sebagai validasi konten produk yang dihasilkan dan bertujuan untuk mengukur kefektifan produk (media) dengan mempertimbangkan usia dan sekumpulan keterampilan dari target responden, sehingga dibutuhkan informasi kejelasan, ketercapaian sasaran (kegunaan) dan relevansi terhadap pemahaman responden (Treser, 2015). Hasil evaluasi ketiga tahapan evaluasi formatif didisajikan pada tabel 3 .

\section{Tabel 3 Hasil Evaluasi Formatif}

\begin{tabular}{|l|l|c|c|c|}
\hline \multirow{2}{*}{ Jenis Evaluasi } & \multicolumn{2}{|c|}{ Responden } & \multicolumn{3}{c|}{ Persentasi Hasil Evaluasi (\%) } \\
\cline { 3 - 5 } & & Clarity & Usefulness & Relevancy \\
\hline One-to-one & Petugas Imigrasi sebanyak 5 orang & $100 \%$ & $100 \%$ & $100 \%$ \\
\hline Smaall group & Pemohon Paspor di Kantor Imigrasi & $100 \%$ & $100 \%$ & $100 \%$ \\
\hline Field trial & Pemohon Paspor di Luar Kantor Imigrasi & $100 \%$ & $100 \%$ & $100 \%$ \\
\hline
\end{tabular}

a. Evaluasi one-to-one, dilakukan untuk mengukur kefektifan multimedia interaktif dari target responden. Pada penelitian ini evaluasi dilakukan terhadap responden dari petugas imigrasi dan pemohon paspor RI. Multimedia interaktif diuji coba terhadap responden, selanjutnya mengisi kuisioner yang mencakup 3 parameter (clarity, usefulness, relevancy). Hasil yang diperoleh mencapai $100 \%$, responden setuju dengan pemahaman ide multimedia interaktif, dapat membantu pengguna untuk menyiapkan berkas dan mengajukan permohonan paspor RI, serta konten yg disediakan sesuai dengan prosedur permohonan paspor RI menggunakan APM di kantor Imigrasi.

b. Evaluasi small group, dilakukan untuk mengetahui seberapa baik pengalaman belajar dalam kelompok responden. Oleh karena itu, evaluasi ini dilakukan terhadap beberapa responden dari kalangan masyarakat yang sedang mengajukan permohonan Paspor RI di kantor Imigrasi. Diuji coba bersama-sama, kemudian beberapa pertanyaan yang diberikan terkait multimedia interaktif ini adalah penggunaan multimedia interaktif menyenangkan dan menarik, memahami tujuan simulasi pembuatan paspor, materi relevan dengan pengajuan manual di kantor imigrasi, meningkatkan 
pemahaman dalam melengkapi berkas-berkas permohonan dan tidak bertele-tele. Seluruh responden menjawab "YA" artinya setuju mengalami hal demikian setelah menggunakan multimedia interaktif ini.

c. Evaluasi Field Trial, dilakukan untuk memastikan media ini berhasil dan layak untuk digunakan sebagai media belajar. Melalui responden yang berbeda, diujikan untuk beberapa masyarakat yang didatangi ke tempat-tempat selain dikantor imigrasi dan hasilnya juga sama yaitu setuju bahwa multimedia interaktif ini cukup jelas ide dan tujuannya, membantu responden memahami pengajuan paspor dan materi yang disampaikan sama dengan yang ada di kantor imigrasi.

\section{Evaluasi Sumatif}

Evaluasi sumatif adalah evaluasi multimedia interaktif simulasi panduan APM oleh pengguna. Pengguna dikategorikan berumur minimal 17 tahun, dengan pengambilan responden sebanyak 83 responden melalui online (media sosial) dan offline. Evaluasi sumatif didasarkan pada 3 parameter yaitu persepsi (perception), pembelajaran (learning) dan kemampuan (performance) ("The ADDIE Model Infographic," 2017). Persentase pencapaian persepsi, pembelajaran dan peningkatan pemahaman responden terhadap informasi yang disajikan pada multimedia interaktif ditentukan berdasarkan formula statistik pada persamaan (1) (Sugiyono, 2016).

$$
\text { Persentase }=\frac{\text { Jumlah }}{\text { Total }} x 100 \%
$$

Dimana: jumlah merupakan frekuensi jawaban dari sebuah soal dan total merupakan total dari jumlah total sample.

Berdasarkan pengumpulan data melalu kuisioner dengan menggunakan formula (1), maka diperoleh ratarata hasil persentasi masing-masing parameter seperti disajikan pada tabel 4.

Tabel 4 Hasil Evaluasi Sumatif

\begin{tabular}{|l|l|c|}
\hline No. & \multicolumn{1}{|c|}{$\begin{array}{c}\text { Parameter } \\
\text { Pengujian }\end{array}$} & $\begin{array}{c}\text { Persentasi Hasil } \\
\text { Evaluasi (\%) }\end{array}$ \\
\hline 1 & Perception & 99,2 \\
\hline 2 & Learning & 95,5 \\
\hline 3 & Performance & 98,66 \\
\hline
\end{tabular}

Berdasarkan hasil pada tabel 4, diperoleh rata-rata persentase pencapaian persepsi, pembelajaran dan peningkatan pemahaman responden sebesar 97,66\%. Hal ini dapat diartikan sebagaimana responden setuju bahwa multimedia interaktif yang dihasilkan memenuhi 3 kriteria yang dimaksud. Masing-masing persentase pencapaian parameter digambarkan pada grafik seperti ditunjukkan pada gambar 5. 


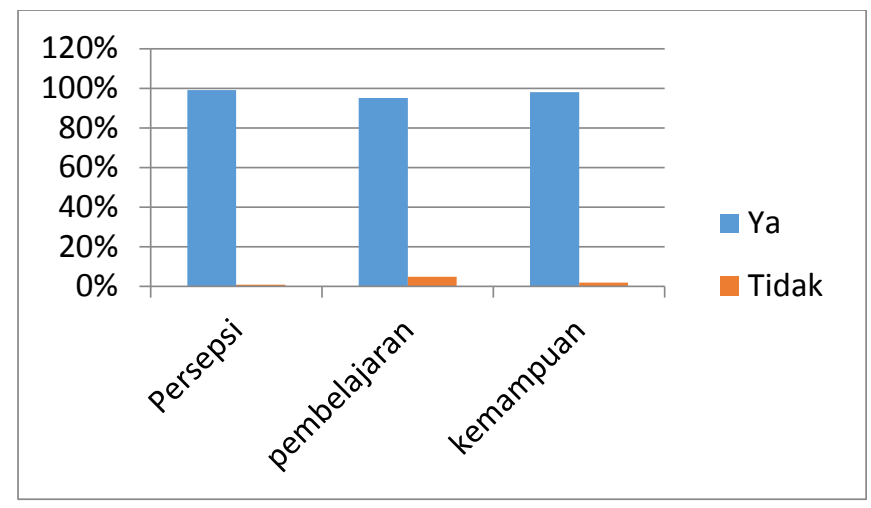

Gambar 5 Grafik Persentase Evaluasi Sumatif

Oleh karena itu, multimedia interaktif simulasi panduan APM menurut pengguna dapat membantu masyarakat dalam memahami dan mempersiapkan pengguna ketika mengajukan permohonan paspor dengan APM, memberikan informasi tentang paspor dan APM, serta meningkatkan kemampuan pengguna dalam mengajukan paspor dengan APM.

\section{KESIMPULAN}

Kesimpulan dalam penelitian ini adalah:

a. Berdasarkan hasil analisis kebutuhan tentang informasi pengajuan permohonan paspor RI bahwa 69, 87\% pemohon belum mengetahui prosedur permohonan paspor melalui aplikasi APM. Media informasi yang digunakan untuk mengetahui permohonan paspor menggunakan aplikasi APM adalah melalui petugas imigrasi, keluarga, teman dan internet.

b. Multimedia interaktif tentang simulasi permohonan paspor RI menggunakan APM dihasilkan sebagai salah satu media informasi bagi masyarakat dengan menerapkan model ADDIE sebagai berikut:

Multimedia interaktif yang dihasilkan dikemas dalam format .swf dan .exe.

$\checkmark$ Multimedia interaktif menerapkan fitur tombol navigasi untuk memfasilitasi interaktifitas pengguna dengan berbagai bentuk konten yaitu teks, gambar dan video animasi 2D sebagai simulasi kelengkapan berkas dan prosedur permohonan paspor RI.

Video animasi 2D yang dihasilkan ada 6 video dalam bentuk simulasi yang terdiri dari video informasi paspor, lokasi APM, berkas paspor, penggunaan aplikasi APM, foto dan wawancara, dan penerimaan paspor.

$\checkmark$ Hasil evaluasi formatif adalah validasi informasi prosedur pengajuan permohonan paspor menggunakan aplikasi APM oleh petugas imigrasi kelas II Tj. Balai Karimun bahwa 100\% menyatakan setuju atau sesuai dengan yang ada di kantor imigrasi.

$\checkmark$ Hasil evaluasi sumatif adalah respon dari masyarakat yang diasumsikan akan mengajukan permohonan paspor, menyatakan bahwa 97,66\% setuju terhadap multimedia interaktif sebagai media informasi yaitu berdasarkan unsur persepsi, pembelajaran, dan kemampuan produk yang dihasilkan.

64 | Evaliata Br Sembiring et al. : Multimedia Interaktif: Media Belajar Membuat Paspor RI... 
c. Berdasarkan hasil evaluasi formatif dan sumatif, multimedia interaktif yang dihasilkan dapat digunakan sebagai media belajar untuk membantu masyarakat dalam melengkapi berkas dan melaksanakan pengajuan paspor RI sesuai dengan pelaksanaan nyata di kantor Imigrasi.

\section{DAFTAR PUSTAKA}

Ahmad, S., \& Bunga, D. A. (2015). Pengembangan Media Simulasi Interaktif Berbasis Web untuk Meningkatkan Aktivitas Belajar Peserta Didik. Prosiding Pertemuan Ilmiah XXIXHFI Jateng \& DIY, 192-195. Retrieved from https://studylibid.com/doc/907975/full-pengembangan-media-simulasiinteraktif---hfi-diy

Branch, R. M. (2009). Instructional Design: The ADDIE Approach. Retrieved from https://www.springer.com/gp/book/9780387095059

Oka, G. P. A. (2017). Media dan Multimedia Pembelajaran (1st ed.). Retrieved from https://issuu.com/aryaoka/docs/media_dan_multimedia_pembelajaran_v

Oktafitriani, H., Hermana, G., Perdana, M. F., \& Yesmaya, V. (2016). Web Based Interactive Multimedia Applications in the Resturant “Tea Addict.” JUrnal Teknik Dan Ilmu Komputer, 5(18), 203-216. Retrieved from http://ejournal.ukrida.ac.id/ojs/index.php/JTIK/article/view/1138

Pratomo, A., \& Irawan, A. (2015). Pengembangan Media Pembelajaran Interaktif Berbasis Web Menggunakan Metode Hannafin dan Peck. Positif, 1(1), 18-28.

Sembiring, E. B., Wahyuni, D., \& Anurogo, W. (2018). Multimedia Interaktif Pengenalan Hewan dan Tumbuhan Langka Menggunakan Model Tutorial. Journal of Digital Education, Communication, and Arts, 1(2), 103-112. Retrieved from https://jurnal.polibatam.ac.id/index.php/DECA/article/view/839/561

Sinta, G., \& Sembiring, E. B. (2017). Multimedia Interaktif untuk Promosi Produk pada Pegadaian Menggunakan Metode Godfrey. Teknomatika, 9(2), 11-27. Retrieved from http://teknomatika.stmikayani.ac.id/wp-content/uploads/2017/08/2.-Glara-Sinta-Multimedia-Interaktifuntuk-Promosi-Produk-pada-Pegadaian-Menggunakan-Metode-Godfrey.pdf

Sugiyono. (2016). Metode Penelitian Kuantitatif, Kualitatif dan $R \&$ D. Bandung: Alfabet.

The ADDIE Model Infographic. (2017). Retrieved from https://elearninginfographics.com/the-addie-modelinfographic/

Treser, M. (2015). Getting To Know ADDIE: Part 5 - Evaluation. Retrieved from https://elearningindustry.com/getting-know-addie-evaluation

Widodo, B., \& Hadi, S. (2017). Panduan Aplikasi Anjungan Paspor Mandiri. Kantor Imigrasi Kelas II Tanjung Balai Karimun. 